\title{
EDQM-HC Pharmaceutical Dosage Form Terminology
}

National Cancer Institute

\section{Source}

National Cancer Institute. EDQM-HC Pharmaceutical Dosage Form Terminology. NCI

Thesaurus. Code C150103.

Terminology subset about the physical manifestation of a product that contains the active ingredient(s) and/or inactive ingredient(s) that are intended to be delivered to the patient. Note: 'Pharmaceutical dose form' and 'Dosage form' are synonyms.

'Pharmaceutical dose form' can refer to the administrable dose form or the manufactured dose form, depending on the product that it is describing. 